\title{
Analysis of Contextual Computer-aided Design (CAD) Exercises
}

\author{
Mrs. Elif Ozturk, Texas A\&M University \\ Dr. Bugrahan Yalvac, Texas A\&M University
}

Dr. Bugrahan Yalvac is an associate professor of science education in the Department of Teaching, Learning, and Culture at Texas A\&M University, College Station. He received his Ph.D. in Science Education from Pennsylvania State University in 2005. Prior to his current position, he worked as a learning scientist for the VaNTH Engineering Research Center at Northwestern University for three years. Yalvac's research is in STEM education, 21st century skills, and design and evaluation of learning environments informed by the How People Learn framework.

\section{Dr. Xiaobo Peng, Prairie View A\&M University \\ Miss Lauralee Mariel Valverde, Texas A\&M University \\ Mr. Prentiss Dwight McGary, Prairie View A\&M University \\ Dr. Michael Johnson, Texas A\&M University}

Dr. Michael D. Johnson is an assistant professor in the Department of Engineering Technology and Industrial Distribution at Texas A\&M University. Prior to joining the faculty at Texas A\&M, he was a senior product development engineer at the 3M Corporate Research Laboratory in St. Paul, Minnesota. He received his B.S. in Mechanical Engineering from Michigan State University and his S.M. and Ph.D. from the Massachusetts Institute of Technology. Dr. Johnson's research focuses on design tools; specifically, the cost modeling and analysis of product development and manufacturing systems; computer-aided design methodology; and engineering education. His work has been published in the International Journal of Production Economics, IEEE Transactions on Engineering Management and The Journal of Engineering Design. 


\title{
Analysis of Contextual Computer-aided Design Exercises
}

\begin{abstract}
Computer-aided Design (CAD) technologies are an essential part of modern design endeavors. In today's industry, engineers use CAD models throughout their work. This makes CAD education crucial. However current CAD education has typically focused on narrow skills related to particular CAD software. The skills necessary to adapt new CAD software and effectively utilize the existing models in modified designs are not the primary emphasis in CAD education. In this paper, the most recent findings of a three-year NSF supported iterative project are discussed. The project goals are to examine the role of adaptive expertise in CAD modeling and investigate the impact of a learner-centered contextual exercise on students' modeling behavior and other educational outcomes.
\end{abstract}

This paper builds on previously reported work. Findings that combine: participating students' responses to an Adaptive Expertise Survey (AES), coded interviews with students and practicing engineers, and the participants' demographic information are reported. Research activity participants include students from Texas A\&M University (TAMU) and Prairie View A\&M University (PVAMU). At each campus, a control group and an experimental group were formed to complete modeling exercises. Students in the experimental group completed a contextual exercise and created CAD models based on some objects that the students were familiar with and frequently used in their daily lives. Students in the control group were asked to model an object that was similar to a textbook exercise. A summary of the data collected and the statistical relationships among the study variables are presented. The study's context and implications for CAD education are discussed.

\section{Introduction}

In many industries, computer-aided design (CAD) tools are pervasively used throughout the development process ${ }^{1}$. Therefore, today's engineering students will go into such a professional field where CAD tools are ubiquitous and available in multiple platforms ${ }^{2}$. This makes it essential for engineers to be able to adapt to new challenges and new platforms to generate innovative solutions. To achieve this goal, effective use of CAD tools that create diverse experiences in engineering education is required. However, most CAD instruction is focused on declarative knowledge that is related to the specific steps required to perform certain tasks in particular CAD platforms ${ }^{3,4}$. This is in contradiction with the strategic knowledge associated with the CAD expertise ${ }^{5}$. This strategic knowledge requires the organization of CAD models and the communication of design intent ${ }^{3,5,6}$. In addition, this strategic knowledge should enable students to perform effectively in new CAD software and platforms; it should involve an expertise that is adaptive. Lang et al. ${ }^{5}$ note the transferability of CAD expertise based on procedural knowledge. Hence, in CAD training it is important to understand how CAD tools can be integrated properly to improve students' adaptive expertise (AE) skills. AE is the term that defines capabilities of both being innovative and adaptive to new challenges while also holding the content knowledge associated with expertise ${ }^{7}$. 


\section{Expertise}

People who have developed an expertise in a field are efficient problem-solvers and appropriately apply their understanding ${ }^{8}$. Experts differ from the novices not simply because of their general abilities, but because of the ways they acquire the knowledge in the field, and the way they organize, represent, and interpret this knowledge ${ }^{8}$. In a study that analyzed novices' and experts' problem solving processes ${ }^{9}$, it was found that the experts were better at processing information and they spent more time on data gathering and problem solving ${ }^{10}$. Experts take more complex actions in solving problems within a design related setting and they are more likely to use non-concrete solutions and analogies than novices ${ }^{11}$. In addition, experts produce more cognitive actions and are better able to organize their knowledge ${ }^{12}$. To date, little work has been done examining expertise related to CAD modeling procedures. Two early studies noted the transferability (or adaptive nature) of procedural knowledge ${ }^{5,13}$. In another study ${ }^{14}$, expert modelers are evaluated to determine if there is a "common modeling procedure." Other work ${ }^{15}$ revealed that expert instruction can lead the students to adopt a significant number of expert modeling strategies.

Traditional assessments on students' competency and expertise focus on specific tasks and problems rather than evaluating students' metacognitive skills or their epistemological positions regarding the subject matter they are learning. However, metacognition and epistemic positions are some characteristics that are critical for effective use of modern CAD programs ${ }^{15,16}$ that should be taken into consideration. Engineering education in the $21^{\text {st }}$ century should be less instructor focused ${ }^{17}$, and be more focused on students' cognition and epistemic positions in light of more learner-entered pedagogies. In addition, students should be encouraged to develop selfregulation and metacognitive skills, and more self-learning and monitoring ${ }^{18}$. In acknowledgement of the essence of these learning outcomes, it is noteworthy to mention that there are two kinds of expertise and not all experts are equal by means of their adaptive abilities. Hatano and Inagaki ${ }^{19}$ defined these two kinds of experts: routine experts and adaptive experts.

\section{Routine versus Adaptive Expertise}

In one's daily life, the same procedure can be carried out again and again to accomplish a task; if this procedure is performed many times, a person can become quite skilled at completing that procedure. However, that skill is useful and effective if the context and the discourse are kept unchanged; i.e., the same set of materials and the devices are available. Thus people may become routine experts in performing the procedure, but not necessarily adaptive ones. Routine experts perform outstandingly in terms of the speed, accuracy, and automaticity of the performance, yet they may lack flexibility and adaptability to the new problems when they are presented in a new context and a discourse. Nevertheless, people do not hesitate to call them experts, since their procedural skills are highly effective for solving everyday problems in a stable environment ${ }^{19}$.

When novices become adaptive experts, they not only implement procedural skills efficiently but also understand the implication of the skills and the nature of their object ${ }^{19}$. Adaptive experts are able to innovate and are efficient in their domain, while routine experts are only efficient. To be an adaptive expert, the ability to innovate and be efficient should be developed together. Learning experiences should promote these two dimensions to grow and develop 
simultaneously ${ }^{20}$. Adaptive experts tend to be more open to inquiry, to use their metacognitive and self-regulation skills, and to hold more advanced personal epistemologies. These characteristics make the adaptive experts flexible, innovative, and creative particularly in novel situations $^{21}$.

Adaptive experts often hold more sophisticated personal epistemology, which is defined as one's beliefs on, and attitudes towards the nature of the knowledge in the field and its generation. Adaptive experts believe that the knowledge in their field is dynamic in nature and it is subject to change as needed. They view the domain knowledge as not static or fixed, yet dynamic and subject to change. These characteristics of adaptive experts allow them to be more flexible to adapt the novel situations and to inquire or generate new knowledge immediately. Identifying the $\mathrm{AE}$ characteristics and assessing the adaptive nature of their CAD expertise will greatly inform and enhance the quality of CAD education.

\section{Study purpose}

This work will reevaluate the first step in a project to examine the adaptive nature of CAD expertise and its role on modeling behavior. An AE instrument developed by Fisher and Peterson $^{22}$ is assessed and used to capture students' AE at two universities as well as that of several practicing engineers. In addition, this study attempts to understand the students' AE characteristics while using a CAD tool through examining a contextualized activity. The effect of the contextualized activity on students' AE characteristics is investigated. This study attempts to explore the relations between students' demographics, AE characteristics, and their CAD modeling attributes. The ultimate goal is to enhance the students' learning experiences to help them develop AE in CAD.

\section{Methods}

\section{Participants and data collection}

To date, the Adaptive Expertise Survey (AES) has been administered to 200 students at Texas A\&M University (TAMU) and Prairie View A\&M University (PVAMU) campuses and 14 engineers practicing in industry. The AES included demographic questions and $42 \mathrm{AE}$ items assessed on a 6-point Likert-scale ${ }^{22}$. Three parallel forms were designed for the two campuses and for the industry participants. A sample student form including demographic questions and the AE survey items is in the Appendix-A. The Likert-scale questions remained the same across the forms, but the demographic questions were stated differently according to the participants' characteristics.

Over the last two semesters, students who enrolled in the CAD courses in the two campuses participated in the project activities. Experimental groups completed the contextualized activity and the control groups completed traditional CAD activities. Students in the experimental group were asked to bring a familiar object to model in CAD tools while the students in the control group were asked to model an unfamiliar three dimensional object which was available in their textbook as a two dimensional drawing. Students were given an hour to model the objects in the CAD software. The computer screens students used were recorded using the screen capturing 
software Camtasia. Each student in both groups were interviewed before and after their modeling exercises. Each interview lasted around 8-12 minutes (total pre and post). The interview protocols are presented in the Appendix-B.

Two of the authors were the course instructors. One of our researchers who was not the course instructor attended the class meetings at the two campuses to invite the students to participate in the study, explained the study purpose, and administered the IRB approved human consent forms prior to collecting data. Students were informed that their responses were confidential and they would not be shared with their course instructors until their final course grades were submitted. Students who agreed to participate signed the consent forms and then completed the AES. Later in the semester, the modeling exercises were implemented in each class. During the modeling exercises, a designated member of the research team interviewed the students and recorded the conversations. The course instructor did not interview the students. Students were given one hour to work on their modeling exercise. Industry participants were invited to the study via email and personal contacts. They were asked to review the e-copy of the IRB approved consent form and provided their consent by signing the form if they agreed to participate. The industry participant consent forms and the completed surveys were collected by one of our researchers via email. The demographic questionnaire and the AES data were organized in a database.

The recorded interviews were transcribed verbatim. One of the researchers analyzed the transcriptions using the constant comparative method ${ }^{23,24}$. This researcher read the transcriptions several times and employed open and axial coding followed by selective coding. The incidents students described were coded and categorized. The codes illustrated the AE characteristics of the students as proposed by Fisher and Peterson ${ }^{22}$. The responses associated with each code were tabulated and these results were entered in the database to facilitate the statistical analyses.

The database included all the data collected from the AES with the engineers and the students as well as the pre and post interviews with the students. SPSS was used to analyze the data. In Table 1, the number of participants and the activities they completed are summarized. All participants including the students and engineers completed the AES.

Table 1. Number of participants and the activities they completed

\begin{tabular}{lccccc} 
& \multicolumn{2}{c}{ Students } & \multicolumn{2}{c}{ Engineers } \\
& TAMU & PVAMU & Total & Total \\
(Fall 2011, & $\begin{array}{c}\text { (Fall 2011, } \\
\text { spring and fall }\end{array}$ & $\begin{array}{c}\text { Students } \\
\text { spring and fall }\end{array}$ & & \\
& 2012) & 2012) & & & \\
\hline AES completed & 97 & 103 & 200 & 14 & 214 \\
$\begin{array}{l}\text { Contextualized } \\
\text { Exercise }\end{array}$ & 10 & 7 & & 9 & \\
Traditional & 10 & 7 & & & \\
Exercise & & & & & \\
\hline
\end{tabular}




\section{Findings}

\section{Reevaluating the survey}

In an earlier work, the authors discussed the reliability and validity of the AES ${ }^{25}$. The authors reported the results of confirmatory factor analysis (CFA) and exploratory factor analysis (EFA). In the present study the authors repeat the analyses with the new data collected.

In the CFA, the analyses examined if the original survey dimensions (multiple perspectives, goals and beliefs, metacognition, and epistemology) Fisher and Petersen ${ }^{22}$ proposed would be extracted with this study's data. The number of factors was set as four (that represents the number of survey dimensions). The pattern matrix indicating the "factor structure coefficients" is presented in Table 2. Higher positive structure coefficients mean the item is well defined by that factor which also defines the correlation between the items and the factors ${ }^{26}$.

Table 2. The pattern coefficient matrix of the CFA with four factors

\begin{tabular}{|c|c|c|c|c|}
\hline \multirow[t]{2}{*}{ Items } & \multicolumn{4}{|c|}{ Factors } \\
\hline & I & II & III & IV \\
\hline (Q1) & .410 & -.150 & -.079 & -.016 \\
\hline (Q2) & .682 & .019 & -.096 & -.250 \\
\hline (Q3) & -.301 & -.064 & .141 & .509 \\
\hline (Q4) & .207 & .110 & .325 & -.323 \\
\hline (Q5) & -.251 & -.030 & .645 & .108 \\
\hline (Q6) & .564 & .254 & -.163 & -.054 \\
\hline (Q7) & .344 & -.087 & -.216 & .576 \\
\hline (Q8) & .189 & .138 & .279 & -.019 \\
\hline (Q9) & .693 & -.122 & -.091 & .031 \\
\hline (Q10) & .244 & .221 & .035 & .260 \\
\hline (Q11) & .492 & -.291 & -.220 & .305 \\
\hline (Q12) & .304 & .483 & -.060 & -.128 \\
\hline (Q13) & .103 & -.332 & .426 & .037 \\
\hline (Q14) & .331 & .136 & .195 & .147 \\
\hline (Q15) & -.066 & .672 & .029 & .174 \\
\hline (Q16) & -.256 & .009 & .375 & .125 \\
\hline (Q17) & .118 & .411 & .079 & -.071 \\
\hline (Q18) & .179 & .545 & .097 & -.131 \\
\hline (Q19) & .056 & .612 & -.010 & .119 \\
\hline (Q20) & .085 & .127 & .555 & -.064 \\
\hline (Q21) & .346 & -.263 & .253 & .091 \\
\hline (Q22) & .081 & .166 & -.015 & .469 \\
\hline (Q23) & -.193 & .237 & .292 & .370 \\
\hline (Q24) & .553 & .141 & -.094 & .035 \\
\hline (Q25) & .216 & -.006 & .227 & .239 \\
\hline
\end{tabular}




\begin{tabular}{lrrrr} 
(Q26) & $\mathbf{. 5 0 3}$ & .191 & -.191 & .030 \\
(Q27) & -.210 & .289 & .104 & .444 \\
(Q28) & $\mathbf{. 4 5 6}$ & .147 & -.059 & -.228 \\
(Q29) & $\mathbf{. 5 0 6}$ & .124 & -.106 & -.168 \\
(Q30) & $\mathbf{. 5 1 0}$ & .267 & .013 & -.057 \\
(Q31) & -.070 & -.133 & -.165 & -.247 \\
(Q32) & .306 & $\mathbf{. 3 6 3}$ & .059 & .228 \\
(Q33) & -.036 & $\mathbf{. 5 4 1}$ & -.020 & -.024 \\
(Q34) & .249 & -.406 & $\mathbf{. 4 5 9}$ & -.108 \\
(Q35) & -.151 & .206 & $\mathbf{. 3 7 6}$ & -.211 \\
(Q36) & .322 & -.370 & $\mathbf{. 4 4 9}$ & -.005 \\
(Q37) & -.229 & .067 & $\mathbf{. 5 6 3}$ & -.118 \\
(Q38) & -.124 & -.009 & -.021 & $\mathbf{. 6 7 3}$ \\
(Q39) & -.078 & -.058 & $\mathbf{. 5 4 0}$ & .055 \\
(Q40) & .232 & .215 & $\mathbf{. 3 5 4}$ & .035 \\
(Q41) & -.127 & -.093 & -.076 &. $\mathbf{7 1 5}$ \\
(Q42) & -.270 & .192 & $\mathbf{. 7 3 8}$ & -.037 \\
\hline
\end{tabular}

Table 3 lists the items Fisher and Peterson grouped under each sub-dimension and the items that are grouped in our CFA with the most recent data collected. For the item verbiage, please refer to the Appendix-A. Not all items matched perfectly but some are grouped under the same factors. Bolded items are the matching items (e.g., items 5,13, 34, 36, and 39 in multiple perspectives match with the CFA results and the originally reported results by Fisher and Peterson). One reason for the miss-matching items is because the characteristics of the participants Fisher and Peterson used were different from this study's participants. The original surveys sub-dimensions (multiple perspectives, goals and beliefs, metacognition, and epistemology) and their number (4) are kept in order not to substantially change the rationale behind the survey construction. However it was decided not to include the items that did not group into a meaningful subdimension.

Table 3. Items grouped by Fisher and Peterson (2001) versus the CFA for the current study with the most recent data.

\begin{tabular}{|c|c|c|c|}
\hline Multiple perspectives & $\begin{array}{l}\text { Metacognitive self- } \\
\text { assessment }\end{array}$ & Goals and beliefs & Epistemology \\
\hline $\begin{array}{l}\mathbf{5}, \mathbf{1 3}, \mathbf{3 4}, \mathbf{3 6}, \mathbf{3 9}, 1 \\
9,17,21,25,29 .\end{array}$ & $\begin{array}{l}\mathbf{2}, \mathbf{6}, \mathbf{1 0}, \mathbf{1 4}, \mathbf{2 6}, \mathbf{3 0}, 18 \\
22,40 .\end{array}$ & $\begin{array}{l}\mathbf{3 , 7} \mathbf{7}, \mathbf{2 3}, \mathbf{2 7}, \mathbf{3 8}, \mathbf{4 1}, 24 \\
11,15,19,31,32,35\end{array}$ & $\begin{array}{l}\mathbf{1 2}, \mathbf{3 3}, 4,8,16,20, \\
28,37,42 .\end{array}$ \\
\hline 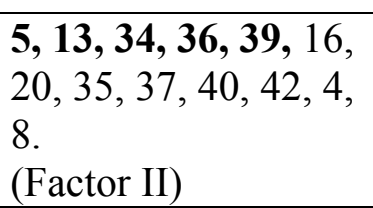 & 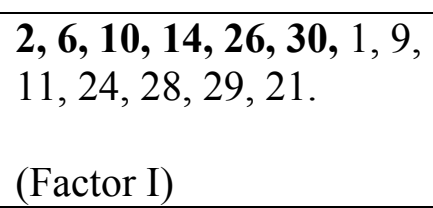 & 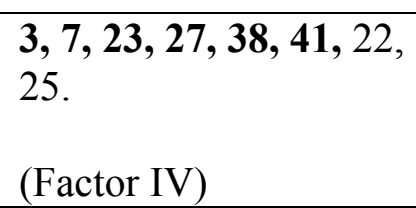 & $\begin{array}{l}\mathbf{1 2}, \mathbf{3 3}, 15,17,18, \\
19,32 . \\
\text { (Factor III) }\end{array}$ \\
\hline
\end{tabular}

Bolded items grouped similarly.

A new CFA was run through structural equation modeling (SEM) in AMOS software to determine if the selected items thoroughly represent the four dimensions proposed by Fisher and Petersen ${ }^{22}$. Figure 1 is the hypothesized CFA model built in AMOS. 


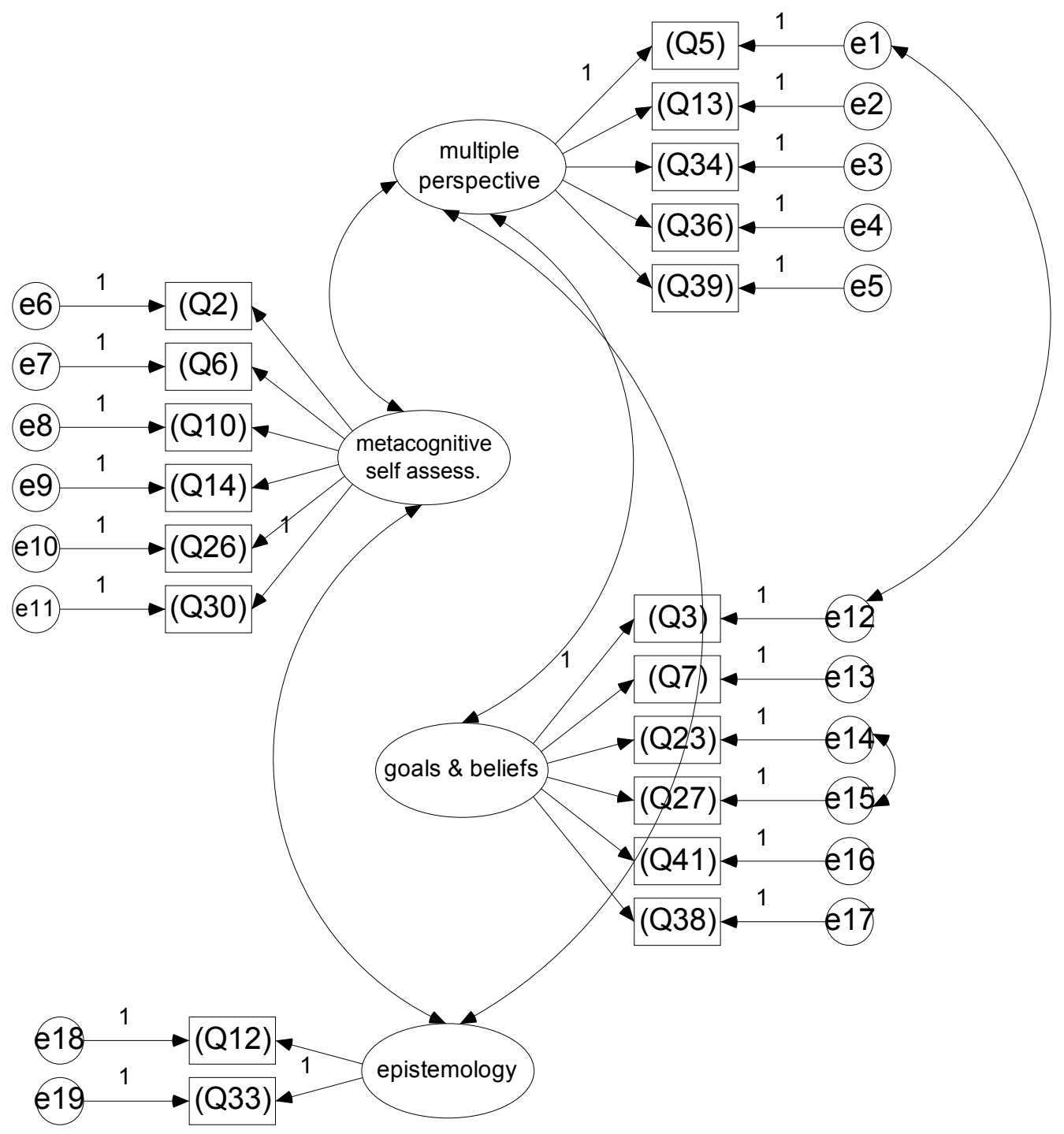

Figure 1. CFA in AMOS software

The hypothesized model appears to be a good fit to the data. The goodness of fit index (GFI) is found 0.905 . GFI values over 0.9 indicate an acceptable fit ${ }^{27}$. For the CFA model, the normed fit index (NFI) value is 0.724 and the comparative fit index (CFI) value is 0.879 . If NFI were equal to " 1 " or CFI were equal to " 1 ," the model would be a perfect fit. Because the values are close to 1, it can reasonably be claimed that the model is a good fit. The Root Mean Square Error of Approximation (RMSEA) value is found to be 0.05 , which also indicates a good fit. After confirming the selected items' strength to define the four dimensions, the authors have decided to use the selected items in computing the students' AE characteristics assessed by the AES. 


\section{2- Relations between the participants' characteristics and their AE scores}

In this section, only the significant differences observed in the statistical analysis will be reported. Both correlations and parametric tests are run to explore the relations between the AES scores, participants' characteristics, and students' interview findings. A total of 214 participants completed the AES (200 students and 14 engineers). A total of 34 students completed the pre and post interviews. For the analyses, 29 students' responses that did not include any missing data are used.

Students' scores (n=29) from the "metacognition" dimension of the AES were correlated with their post interview meta-cognitive characteristics as captured by the interviews $(r(27)=.367$, $p<.05)$.

In the AES, the participants scores (n=214) for the "metacognition" and "multiple perspectives" sub-dimensions $(r(212)=.176, p<.05)$, and "metacognition" and "epistemology" sub-dimensions $(r(212)=.264, p<.05)$ were significantly correlated with one another. AES scores for the "goals and beliefs" and "multiple perspectives" sub-dimensions $(\mathrm{n}=214)$ were also significantly correlated $(r(212)=.244, p<.05)$.

ANOVA tests for the demographic characteristics and the coded interview data found that the seniors $(N=13, M=6.69, S D=1.97)$ conveyed more AE related characteristics than the sophomores $(N=4, M=3.25, S D=1.26, F(3,25)=4.85, p=.009)$. The same pattern was evident in the pre interview that the sophomores $(N=4, M=2.00, S D=.00)$ conveyed less AE characteristics than the seniors $(N=13, M=4.46, S D=1.13, F(3,25)=4.36, p=.013)$. In the post-interviews, the sophomores' $(N=4, M=.50, S D=.58)$ conveyed more AE related epistemologies than the seniors $(N=13, M=.00, S D=.00, F(3,25)=3.74, p=.024)$.

When comparing the students' scores across the two campuses $\left(N_{\text {TAMU }}=17, N_{\text {PVAMU }}=12\right)$ for the coded interview data, it is found that the students at TAMU conveyed more AE related characteristics than the students at PVAMU $\left(M_{\mathrm{TAMU}}=6.53, S D_{\mathrm{TAMU}}=1.91, M_{\mathrm{PVAMU}}=4.50\right.$, $\left.S D_{\text {PVAMU }}=1.68, F(1,27)=8.77, p=.006\right)$. For the pre-interview data, the TAMU students conveyed more AE characteristics for the "goals and beliefs" dimension than the PVAMU students $\left.\left(M_{\mathrm{TAMU}}=.82, S D_{\mathrm{TAMU}}=.88, M_{\mathrm{PVAMU}}=.17, S D_{\mathrm{PVAMU}}=.39\right) F(1,27)=5.80, p=.023\right)$. While the goals and beliefs were the only statistically different dimension mentioned in the preinterviews for the two campuses, more than one sub-dimension difference in the post-interviews was observed. Students in TAMU $\left(N_{\mathrm{TAMU}}=17\right)$ reported more overall AE characteristics than the students in PVAMU $\left(N_{\mathrm{PVAMU}}=12\right)$ during the post-interviews $\left(M_{\mathrm{TAMU}}=2.35, S D_{\mathrm{TAMU}}=1.06\right.$, $\left.M_{\text {PVAMU }}=1.00, S D_{\text {PVAMU }}=.95, F(1,27)=12.47, p=.002\right)$. For the multiple perspectives AE characteristics mentioned in the post-interviews, a statistically significant difference between the students in two campuses was found $\left(M_{\mathrm{TAMU}}=.76, S D_{\mathrm{TAMU}}=.75, M_{\mathrm{PVAMU}}=.33, S D_{\mathrm{PVAMU}}=.49\right)$ $F(1,27)=3.01, p=.094)$. The metacognitive $\mathrm{AE}$ characteristics communicated by the students in the post-interviews were also significantly different for the two groups of students $\left(M_{\mathrm{TAMU}}=1.47, S D_{\mathrm{TAMU}}=.72, M_{\mathrm{PVAMU}}=.42, S D_{\mathrm{PVAMU}}=.51, F(1,27)=18.92, p=.00\right)$. 


\section{Discussion and Conclusion}

In this study, it was first evaluated if the AES items meaningfully assessed the participants' AE characteristics as they were reported by Fisher and Petersen ${ }^{22}$. The CFA results indicated that there are items matching with the originally reported factors. Those matching items were then used to compute the participants' AE scores. Correlations and f-tests were then used to find significant results among demographic data, AE scores, and coded interview responses.

It was expected that the students' reported AE characteristics in the interviews would match with their AES sub-dimension scores. Only the students" "metacognitive" characteristics extracted from the post interviews matched with the students" "metacognitive" sub-dimension scores in the AES. Metacognition is the ability to self assess or to monitor self-understanding. When a person's metacognition is activated, he or she questions his or her own understanding and easily recognizes areas where the knowledge is incomplete ${ }^{22}$. As these findings indicate, it can be concluded that student participants in this study assessed their knowledge more effectively and have recognized where their knowledge is incomplete after they complete their modeling exercise as reported in the post-interviews.

F-tests (ANOVA) were used to see if the groups were different from each other in terms of the AES scores, the interview findings, and students' demographic characteristics (e.g., school, rank, sex, etc). Senior students conveyed more AE characteristics than the sophomores in the coded interview data, this was especially true in the pre-interview data. As expected, when the students were more experienced with the modeling practice, their metacognitive adaptive expertise characteristics were enhanced. The same conclusion is also evident when the two campuses are compared. At TAMU, most students were seniors while at PVAMU, the students were mostly freshmen and sophomores. For all the observed statistically significant differences, students in TAMU reported higher AE scores than the students in PVAMU. These results shed light on research conducted to enhance CAD curriculum. These findings show that metacognitive skills are a good indicator of developing adaptive expertise and the educators should consider promoting metacognitive skills in CAD education.

Although significant results are presented, the number of students $(N=34)$ who conducted the contextualized modeling activity was relatively low for the quantitative analyses. Future work will consist of collecting more data from the students and engineers. As the participant pool increases in number, more precise and clear results should be generated by these analyses.

\section{Acknowledgement}

This material is supported by the National Science Foundation under EEC Grant Numbers 1129403 and 1129411. Any opinions, findings, conclusions, or recommendations presented are those of the authors and do not necessarily reflect the views of the National Science Foundation. 


\section{References}

[1] Field, D.A., (2004). Education and training for cad in the auto industry. Computer-Aided Design, 36 (14), 1431-1437.

[2] Johnson, M.D. \& Diwakaran, P., (2011). An educational exercise examining the role of model attributes on the creation and alteration of cad models. Computer \& Education, 57, 1749-1761.

[3] Hamade, R.F., Artail, H.A. \& Jaber, M.Y., (2007). Evaluating the learning process of mechanical cad students. Computers \& Education, 49 (3), 640-661.

[4] Ye, Z., Peng, W., Chen, Z. \& Cai, Y., (2004). Today's students, tomorrow's engineers: An industrial perspective on cad education. Computer-Aided Design, 36 (14), 1451-1460.

[5] Lang, G.T., Eberts, R.E., Gabel, M.G. \& Barash, M.M., (1991). Extracting and using procedural knowledge in a cad task. IEEE Transactions on Engineering Management, 38 (3), 257-268.

[6] Anderson, L.W., Krathwohl, D.R. \& Bloom, B.S., (2001). A taxonomy for learning, teaching, and assessing : A revision of bloom's taxonomy of educational objectives, Complete ed. New York: Longman.

[7] Mckenna, A.F., (2007). An investigation of adaptive expertise and transfer of design process knowledge. Journal of Mechanical Design, 129 (7), 730-734.

[8] Bransford, J.D., Brown, A.L. \& Cocking, R.R., (2000). How people learn: Brain, mind, experience, and school: Expanded edition Washington, D.C.: National Academy Press.

[9] Brand-Gruwel, S., Wopereis, I. \& Vermetten, Y., (2005). Information problem solving by experts and novices: Analysis of a complex cognitive skill. Computers in Human Behavior, 21, 487-508.

[10] Atman, C.J., Adams, R.S., Cardella, M.E., Turns, J., Mosborg, S. \& Saleem, J., (2007). Engineering design processes: A comparison of students and expert practitioners. Journal of Engineering Education, 96 (4), 359-379.

[11] Ball, L.J., Ormerod, T.C. \& Morley, N.J., (2004). Spontaneous analogising in engineering design: A comparative analysis of experts and novices. Design Studies, 25, 495-508.

[12] Kavakli, M. \& Gero, J.S., (2002). The structure of concurrent cognitive actions: A case study on novice and expert designers. Design Studies, 23, 25-40.

[13] Bhavnani, S.K., Garrett, J.H. \& Shaw, D.S., (1993). Leading indicators of cad experience. Proceedings of the fifth international conference on Computer-aided architectural design futures. Pittsburgh, Pennsylvania, United States.

[14] Hartman, N.W., (2005). Defining expertise in the use of constraint-based cad tools by examining practicing professionals. Engineering Design Graphics Journal, 69 (1), 6-15.

[15] Chester, I., (2007). Teaching for cad expertise. International Journal of Technology and Design Education, 17 (1), 23-35.

[16] Rynne, A. \& Gaughran, W., (2008). Cognitive modeling strategies for optimum design intent in parametric modeling. Computers in Education Journal, 18 (1), 55-68.

[17] Hadim, H.A. \& Esche, S.K., (2002). Enhancing the engineering curriculum through project-based learning. Frontiers in Education. Boston, MA.

[18] Harris, M. \& Cullen, R., (2009). A model for curricular revision: The case of engineering. Innovative Higher Education, 34 (1), 51-63. 
[19] Hatano, G. \& Inagaki, K., (1986). Two courses of expertise. In Stevenson, H.W., Azuma, H. \& Hakuta, K. eds. Child development and education in japan. New York: W.H. Freeman, 262-272.

[20] Schwartz, D.L., Bransford, J.D. \& Sears, D., (2005). Efficiency and innovation in transfer. In Mestre, J.P. ed. Transfer of learning from a modern multidisciplinary perspective. Greenwich, CT :: IAP.

[21] Hatano, G. \& Oura, Y., (2003). Commentary: Reconceptualizing school learning using insight from expertise research. Educational Researcher, 32 (8), 26-29.

[22] Fisher, F.T. \& Peterson, P.L., (2001). A tool to measure adaptive expertise in biomedical engineering students. ASEE Annual Conference and Exposition. Albuquerque, NM.

[23] Creswell, J.W., (2007). Qualitative inquiry and research design: Choosing among five approaches Thousand Oaks, CA: Sage.

[24] Glaser, B.G. \& Strauss, A.M., (1967). The discovery of grounded theory: Strategies for qualitative research Chicago, IL: Aldine.

[25] Johnson, M.D., Ozturk, E., Johnson, J., Yalvac, B. \& Peng, X., (Year). Assessing an adaptive expertise instrument in computer-aided design (cad) courses at two campusesed.^eds. American Society for Engineering Education (ASEE) Annual Conference and Exposition, San Antonio, TX.

[26] Gorsuch, R.L., (1974). Factor analysis Philadelphia, PA: W. B. Saunders Company.

[27] Kline, R.B., (2011). Principles and practice of structural equation modeling New York, NY: The Guilford Press. 


\section{Appendix-A}

\section{Adaptive Expertise Related to Computer Aided Design (CAD) Student Survey Form}

(Some demographic questions were different in the engineering survey and in the student survey administered at one of the two campuses).

Thank you for participating in this study.

This survey includes two sections. Section I asks for your demographic information. Section II includes some opinion and attitude questions towards the characteristics of adaptive expertise. Section II items are to explore your personal views and experiences. Your responses to this survey will remain confidential and will not be shared with anyone other than the researchers.

\section{Section I: Demographic Questionnaire}

Please answer the below questions by checking the appropriate boxes or filling in the necessary field:

\begin{tabular}{|c|c|c|c|c|c|}
\hline 1 & Name - Last Name (write in) & & & & \\
\hline 2 & Sex (check) & Male & ale & & \\
\hline 3 & Age (write in) & & & & \\
\hline 4 & Rank/ level in college (check) & Freshman & Sophomore & Junior & Senior \\
\hline 5 & Major (write in) & & & & \\
\hline 6 & $\begin{array}{l}\text { Have you had a professional work } \\
\text { experience related to engineering } \\
\text { (e.g., internship, co-op, etc.)? }\end{array}$ & Yes & No & & \\
\hline 7 & $\begin{array}{l}\text { Have you had any technical } \\
\text { employment and research } \\
\text { experience related to engineering } \\
\text { (e.g., machines shops, labs, } \\
\text { project tasks, etc.) }\end{array}$ & Yes & No & & \\
\hline
\end{tabular}

\section{Please go to next page for survey questions}


Section II: Adaptive Expertise Questionnaire (Fisher and Peterson, 2001)

In this section, please read each item carefully and indicate your position by circling one of the numbers in the 6 point scale as 1 (strongly disagree), 2 (disagree), 3 (slightly disagree), 4 (slightly agree), 5 (agree), and 6 (strongly agree). Note that number 6 on the right designates the highest agreement and number 1 on the left designates the lowest agreement with the item.

\section{1}

1. I create several models of an engineering problem to see which one I like best.

2. As I learn, I question my understanding of the new information.

1

3. I feel uncomfortable when I cannot solve difficult problems.

4. Knowledge that exists today may be replaced with a new understanding tomorrow

5. Usually there is one correct method in which to represent a problem.

6. I often try to monitor my understanding of the problem.

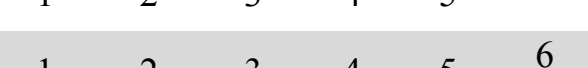

7. I am afraid to try tasks that I do not think I will do well.

8. Most knowledge that exists in the world today will not change.

$\begin{array}{llllll}1 & 2 & 3 & 4 & 5 & 6 \\ 1 & 2 & 3 & 4 & 5 & 6\end{array}$

9. When I consider a problem, I like to see how many different ways I can look at it.

\begin{tabular}{llllllll} 
10. & As a student, I cannot evaluate my own understanding of new material. & 1 & 2 & 3 & 4 & 5 & 6 \\
\hline 11. & Although I hate to admit it, I would rather do well in a class than learn a lot. & 1 & 2 & 3 & 4 & 5 & 6 \\
\hline 12. & Scientists are always revising their view of the world around them. & 1 & 2 & 3 & 4 & 5 & 6 \\
\hline 13. & I tend to focus on a particular model in which to solve a problem. & 1 & 2 & 3 & 4 & 5 & 6
\end{tabular}

14. I rarely monitor my own understanding while learning something new.

$\begin{array}{llllll}1 & 2 & 3 & 4 & 5 & 6 \\ 1 & & & \end{array}$

15. One can increase their level of expertise in any area if they are willing to try.

16. Facts that are taught to me in class must be true.

$\begin{array}{llllll}1 & 2 & 3 & 4 & 5 & 6\end{array}$

17. I am open to changing my mind when confronted with an alternative viewpoint.

18. When I know the material, I can recognize areas where my understanding is incomplete

$\begin{array}{llllll}1 & 2 & 3 & 4 & 5 & 6 \\ 1 & 2 & 3 & 4 & 5 & 6\end{array}$

19. Expertise can be developed through hard work.

20. Existing knowledge in the world seldom changes.

$\begin{array}{llllll}1 & 2 & 3 & 4 & 5 & 6 \\ 1 & 2 & 3 & 4 & 5 & 6 \\ 1 & 2 & 3 & 4 & 5 & 6\end{array}$

21. I rarely consider other ideas after I have found the best answer.

\begin{tabular}{|c|c|c|c|c|c|}
\hline 1 & 2 & 3 & 4 & 5 & 6 \\
\hline 1 & 2 & 3 & 4 & 5 & 6 \\
\hline 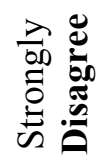 & 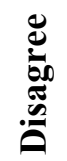 & 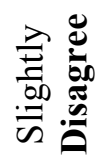 & 㟒 & 苛 & 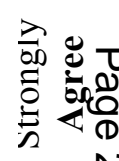 \\
\hline
\end{tabular}


22. I have difficulty in determining how well I understand a topic.

\begin{tabular}{l|l|l|l|l|l}
$\mathbf{1}$ & $\mathbf{2}$ & $\mathbf{3}$ & $\mathbf{4}$ & $\mathbf{5}$ & $\mathbf{6}$ \\
1 & 2 & 3 & 4 & 5 & 6 \\
1 & 2 & 3 & 4 & 5 & 6 \\
1 & 2 & 3 & 4 & 5 & 6 \\
1 & 2 & 3 & 4 & 5 & 6 \\
1 & 2 & 3 & 4 & 5 & 6 \\
1 & 2 & 3 & 4 & 5 & 6 \\
\hline
\end{tabular}

28. Scientific theory slowly develops as ideas are analyzed and debated.

1

29. For a new situation, I consider a variety of approaches until one emerges superior.

30. As I work, I ask myself how I am doing and seek out appropriate feedback.

$\begin{array}{llllll}1 & 2 & 3 & 4 & 5 & 6 \\ 1 & 2 & 3 & 4 & 5 & 6 \\ 1 & 2 & 3 & 4 & 5 & 6 \\ 1 & 2 & 3 & 4 & 5 & 6\end{array}$

34. I solve all related problems in the same manner.

$\begin{array}{llllll}1 & 2 & 3 & 4 & 5 & 6\end{array}$

35. Poorly completing a project is not a sign of a lack of intelligence.

$\begin{array}{llllll}1 & 2 & 3 & 4 & 5 & 6\end{array}$

36. When I solve a new problem, I always try to use the same approach.

37. Scientific knowledge is discovered by individuals.

$\begin{array}{llllll}1 & 2 & 3 & 4 & 5 & 6 \\ 1 & 2 & 3 & 4 & 5 & 6 \\ 1 & 2 & 3 & 4 & 5 & 6\end{array}$

38. When I struggle, I wonder if I have the intelligence to succeed in engineering

$\begin{array}{llll}1 & 2 & 3 & 4\end{array}$

39. There is one best way to approach a problem.

40. I seldom evaluate my performance on a task.

1

41. I feel uncomfortable when unsure if I am doing a problem the right way.

42. Progress in science is due mainly to the work of sole individuals.

$\begin{array}{llllll}1 & 2 & 3 & 4 & 5 & 6 \\ 1 & 2 & 3 & 4 & 5 & 6\end{array}$

\begin{tabular}{ll|lll|l}
1 & 2 & 3 & 4 & 5 & 6
\end{tabular}

Thank you for your time

\section{Please return the form to the researchers.}




\title{
Appendix-B
}

\author{
Interview Protocols
}

\section{Pre-interview Questions}

1. What are the things you consider first when you are asked to model an object? Why?

2. What are the challenges you often encounter in the modeling process?
a. How do you plan to overcome these challenges?

b. Which strategies do you anticipate using?

3. Are you familiar with the object you are going to model today?

4. How important it is to know about the object you are going to model?

- If you are familiar with the object you are modeling or if you use it often in your daily life, would it be easier for you to model it? Why, why not?

\section{Post-interview Questions}

1. The things you considered before you began modeling the object, were they helpful to you in the process? How and why?

2. What challenges did you encounter during the modeling process?

3. How did you overcome the challenges you faced during the modeling process?

4. Was knowing the object or being familiar with it, helpful to you in your modeling process? How and why?

5. How confident are you in your model?

Note: All questions are open ended, some emergent questions may be asked 